\title{
IN VITRO ANTI-PROTOZOAL ACTIVITY OF PROPOLIS EXTRACT AND CYSTEINE PROTEASES INHIBITOR (PHENYL VINYL SULFONE) ON BLASTOCYSTIS SPECIES
}

By

\author{
AMIRA B. MOKHTAR ${ }^{1^{*}}$, EMAN K. EL-GAYAR ${ }^{1}$, EMAN S. HABIB ${ }^{2}$ \\ Department of Medical Parasitology ${ }^{1}$, Faculty of Medicine, and Department of \\ Pharmacognosy ${ }^{2}$, Faculty of Pharmacy, Suez Canal University ${ }^{1,2}$, Ismailia, Egypt \\ ( ${ }^{*}$ Correspondence: ami hagag@yahoo.com) \\ Abstract
}

Blastocystis is one of the commonest enteric protozoan parasites worldwide. Despite its controversial clinical significance, frequent association with symptoms has necessitated treatment of cases with persistent symptoms. For long time, metronidzole (MTZ) was considered as a basic drug for blastocystosis treatment, however reports of treatment failure as well as its well-known side effects has promoted the search for more safe and effective alternatives. In vitro antiprotozoal activity of ethanolic extract of Egyptian propolis and a cysteine protease inhibitor, phenyl vinyl sulfone (PVS) on Blastocystis spp. was assessed through challenging with graded concentrations of propolis extract $(125,250,500 \& 1000 \mu \mathrm{g} / \mathrm{ml})$ and PVS $(100,200$ and $300 \mu \mathrm{g} / \mathrm{ml})$ compared to MTZ $(10,50$ and $100 \mu \mathrm{g} / \mathrm{ml}$ ) and viable parasites were counted after 24, 48 and $72 \mathrm{hr}$. of incubation. Molecular subtyping of Blastocystis spp. was done using subtype specific sequence-tagged site (STS) primers. Propolis extract inhibited the growth of Blastocystis spp. in both of the detected subtypes (ST1 and ST3), which was especially observed in cultures exposed to $500 \& 1000 \mu \mathrm{g} / \mathrm{ml}$ through all incubation periods with the later concentration producing comparable results to MTZ. While PVS showed significant parasite count reduction on ST3 isolates, especially with the highest concentration, however the effect on ST1 isolate was nonsignificant. These findings highlight the potential antiprotozoal activity of propolis extract as a potent natural alternative for MTZ in treatment of blastocystosis.

Key words: Blastocystis spp., in vitro, propolis, phenyl vinyl sulfone.

\section{Introduction}

Blastocystis species (spp.) are singlecelled anaerobic parasites that inhabit the lower intestinal tract of man and many animals (Yoshikawa et al, 2011). It was first described in1912as a harmless yeast and later as a protozoan parasite (Arisu, 2002). This emerging parasite has a worldwide distribution especially in underdeveloped nations, probably due to poor sanitation, exposure to animals and consumption of contaminated food or water (Stensvold et al, 2009) and considered as the most common parasite that can be detected in human stool samples, where its prevalence has shown a dramatic increase in recent years (Souppart et al, 2010). The infection rates ranged from 10$70 \%$ in different countries with high rates in adults than in children (Wong, 2008; El Safady et al, 2014). In Egypt, Blastocystis spp. was the most common identified parasite
(33.3\%) among the patients complaining of GIT symptoms (Rayan et al, 2007).

One of the greatest controversies surrounding Blastocystis was its equivocal association with bowel disease, where it is frequently found not only in GIT symptomatic patients but also in asymptomatic individuals (Tan, 2008b). However, numerous epidemiological, molecular, immunological and animal studies have helped clarify the pathogenic potential of Blastocystis, with evidence strongly suggesting its pathogenic potential (Tan, 2008a). Genetic analysis of Blastocystis spp. revealed presence of up to 17 subtypes (ST), at least 9 of which have been identified in humans where ST1-ST4 account for about $90 \%$ of human infections (Alfellani et al, 2013; Stensvold, 2013). Intestinal manifestations of symptomatic blastocystosis can be variable, ranging from mild diarrheal illness or acute gastroenteritis 
with profuse watery diarrhea to chronic diarrhea (Gupta and Parsi, 2006; Nassir et al, 2004; Shah et al, 2012). Other nonspecific symptoms may be included as anorexia, nausea, vomiting, abdominal pain and flatulence (Jones et al, 2009). Moreover, the association of Blastocystis spp. with irritable bowel syndrome (IBS) and allergic skin disorders has been reported by several studies (Doğruman-AI et al, 2010; Yakoob et al, 2010; Hameed et al, 2011). Blastocystisassociated symptoms are generally selflimiting and may last from 1 to 14 days, however, some infections may persist for months or years if left untreated (Ustün and Turgay, 2005; Tan, 2008b).

Despite the fact that MTZ is the most frequently prescribed drug for treatment of blastocystosis (Dinleyici et al, 2011), yet it was reported to have widely varying rates of efficacy ranging from $0-100 \%$ and often associated with treatment failure as a possible result of drug resistance (Stensvold et al, 2010; Dunn et al, 2012). In addition to its undesirable side effects, MTZ has shown to induce a potential risk of carcinogenic, embryongenic and teratognic effects (Calzada et al, 2007). Hence, there is an urgent need to develop safe and effective alternative antiprotozoal agents to overcome these drawbacks.

Several studies have been conducted to find an effective natural therapy for blastocystosis to avoid exposure to potentially toxic drugs, including screening of plant extracts and plant-derived compounds (Vital and Rivera, 2009; Yakoob et al, 2011; ElDeeb et al, 2012). Propolis is a resinous substance collected by honeybees from plant exudates and used in beehives to seal crakes and as a building insulation material (Greenaway et al, 1990). For a long time, it has been widely used in folk medicine (Bankova, 2005). Recently, it has gained popularity as a food supplement (Monzote et al, 2012). Broad spectrum therapeutic activities of propolis have been described by numerous studies; including anti-inflammatory, anti- microbial, antioxidant (Bankova et al, 2000; Wang et al, 2013), antitumor (Popolo et al, 2009), antiulcer, anti-HIV (Ito et al, 2001) and antihelminthic activities (Hegazi et al, 2007). Major antiprotozoal activities of the propolis were also reported, including antigiardial, antileishmanial, antiplasmodial and antitrypanosomal activities (AbdelFattah and Nada, 2007; Monzote et al, 2012). However, no reports have investigated its effect on Blastocystis spp. until now. The chemical characteristics of propolis have been related to variations in geographical location, source plants and bee species. Generally, the propolis is composed of $50 \%$ plant resins, 30\% wax, $10 \%$ essential and aromatic oils, $5 \%$ pollens and $5 \%$ other organic substances (Huang et al, 2014). Numerous studies have concluded that the therapeutic effects might result of synergistic action of its complex constituents (Sforcin et al, 2005; Bueno-Silva et al, 2013).

Cysteine proteases (CP) of protozoan parasites are enzymes that have been involved in a number of important biological functions including host cell invasion, immune evasion, pathogenesis and virulence (Sajid and McKerrow, 2002). These enzymes have emerged as promising targets for antiparasitic drug development (Atkinson et al, 2009). Non-specific cysteine protease inhibitors (CPIs) such as PVS have shown promising results in treatment of experimental Schistosoma mansoni infection (Abaza et al, 2013). Also, the PVS showed activities against Trypanosoma cruzi (Engel, 1998), Plasmodium falciparum (Pandey et al, 2006) and Toxoplasma gondii (Larson, 2009).

The present study aimed to investigate the in vitro effects of ethanolic extract of Egyptian propolis and a cysteine protease inhibitor, PVS at different concentrations on the growth of Blastocystis parasite.

\section{Patients, Materials and Methods}

Stool samples collection and examination: Fecal samples were collected from acutely GIT symptomatic patients with no history of antibiotic administration, attending the Gas- 
troenterology Outpatient Clinic, The General Hospital, Ismailia, Egypt. Collected samples were examined by wet mount, iodine-stained smear, formalin-ethyl acetate concentration techniques (Garcia, 2007). Samples positive for Blastocystis spp. were further subjected to trichrome and acid-fast Trichrome staining to exclude common pathogenic parasites (Garcia, 2007). In addition, stool culture using Salmonella-Shigella and MacConkey agar were performed to exclude common pathogenic bacteria causing GIT symptoms (Cheesbrough et al, 2006). Only samples positive for Blastocystis without co-infection with other pathogenic parasites or bacteria were included in the study.

In vitro cultivation of Blastocystis parasite: Three Blastocystis-positive samples (isolate I-III) were cultivated in duplicate tubes into Jones' medium without rice starch, supplemented with $10 \%$ horse serum, $100 \mathrm{UI} / \mathrm{ml}$ penicillin, and $100 \mu \mathrm{g} / \mathrm{ml}$ streptomycin at $37^{\circ} \mathrm{C}$ (Leelayoova et al, 2002). Repeated subcultures were done every 3-4 days in fresh medium for about a month (Girish et $a l, 2015)$ to ensure sterile culture with minimum fecal debris.

Molecular subtyping of Blastocystis isolates: Blastocystis DNA was extracted from positive stool cultures with a DNA extraction kit, according to manufacturer's directions (QIAamp; Qiagen Inc., Hilden, Germany).

Polymerase chain reaction using seven pairs of STS primers namely; SB83 (351 bp) for ST1, SB155 (650 bp) for ST2, SB227 (526 bp) for ST3, SB332 (338 bp) for ST4, SB340 (704 bp) for ST5, SB336 (317 bp) for ST6, and SB337 (487 bp) for ST7 (Yoshikawa et al, 2004) were used to identify Blastocystis spp. subtypes according to the method described by Tan et al. (2008).

Propolis extract: Crude brown Egyptian propolis was supplied from an Egyptian honeybee keeper from bees feeding on buds of Egyptian clover or Berseem (Trifolium alexandrinum) as the source plant. Propolis $30 \%$ ethanolic extract was prepared. Briefly,
$30 \mathrm{gm}$ of propolis was cut into small pieces and the volume was completed to $100 \mathrm{ml}$ with $70 \%$ ethanol, with occasional stirring at room temperature. Stirring was repeated twice a week but otherwise it was left in a dark place. After a week, the extract was filtered using Wattman paper number 1 producing a clear dark brown filtrate free of particles. The solvent was evaporated at $40^{\circ} \mathrm{C}$ under reduced pressure to obtain the dry extract which was weighed to calculate the final concentration (Miorin et al, 2003). The extract was dissolved in $70 \%$ ethanol at $10 \mathrm{mg} / \mathrm{ml}$ and stored at $4^{\circ} \mathrm{C}$. The following concentrations of propolis were used for in vitro assessment of its effect on Blastocystis spp.; 125, 250, 500 and $1000 \mu \mathrm{g} / \mathrm{ml}$.

Preparation of PVS and MTZ concentrations: Cysteine protease inhibitor, phenyl vinyl sulfone (Mu-phe-Hph-ch2F; SigmaAldrich, Germany) serial dilutions were prepared as 100,200 and $300 \mu \mathrm{g} / \mathrm{ml}$ of the compound in sterile distilled water. The metronidazole (Flagyl) was used as a reference antiprotozoal drug (Sawangjaroen and Sawangjaroen, 2005). The stock solution of $1 \mathrm{mg} / \mathrm{ml}$ was prepared and stored in a dark bottle at $4^{\circ} \mathrm{C}$. Final concentrations of MTZ were adjusted to $10,50 \& 100 \mu \mathrm{g} / \mathrm{ml}$ (Yakoob et al, 2011).

In vitro experimental design: From each Blastocystis isolate an inoculum size of $2 \times 10^{5}$ parasites $/ \mathrm{ml}$ from cultures in logarithmic growth phase was prepared by counting the number of live parasites using a Neubauer cell counting chamber after staining with $0.4 \%$ Trypan blue solution as an indicator of viability. After calculation of the inoculum volume required from each isolate and the corresponding quantities of propolis extract, PVS and MTZ (according to corresponding concentrations), the amount of the added Jones' medium was calculated to obtain a final volume of $1 \mathrm{ml}$ (Grabensteiner et $a l$, 2008). Non-treated control (NTC) and $70 \%$ ethanol-treated control (ETC) cultures were prepared by the same procedure. Parasites were challenged with a graded concen- 
tration of propolis extract $(125,250,500$ $\& 1000 \mu \mathrm{g} / \mathrm{ml})$, PVS $(100,200 \& 300 \mu \mathrm{g} / \mathrm{ml})$ and MTZ $(10,50 \& 100 \mu \mathrm{g} / \mathrm{ml})$ and viable parasites were counted after $24,48 \& 72 \mathrm{hr}$. All experiments were performed in triplicate.

Effect of propolis extract and PVS on the in vitro growth of Blastocystis spp.: The effect of concentrations of propolis extract, PVS \& MTZ on each Blastocystis isolate was determined by detecting the cytocidal and cytostatic effects to all the viable (unstained) forms of Blastocystis parasite as assessed by Trypan blue solution ( $0.4 \%)$. The cytocidal effect was determined as the lowest concentration in which no viable parasites were seen and no growth was detected $72 \mathrm{hr}$ later when $100 \mu \mathrm{l}$ of the samples with no parasites found were cultured into fresh Jones' medium (Vdovenko and Williams, 2000). While, the cytostatic effect (percentage of growth inhibition) was defined as the reduction of the number of Blastocystis parasite compared to the number of NTC, and was calculated according to the following equation (Ahmed et al, 2015):

Growth inhibition $\%=\underline{a-b} \times 100$ where, $a$ $a=$ mean number of Blastocystis parasite in NTC, $b=$ mean number in treated cultures. Fifty parasites were randomly selected from each culture tube (treated $\&$ untreated) for size measurement at $48 \mathrm{~h}$ after their initial inoculation into Jones' medium and the percentages of granular forms were calculated (Tan et al, 2008).

Statistical analysis: Data were reported as mean counts \pm standard deviation. Statistical analyses were done using statistical software program SPSS 16.0. The independent sample $t$ test was used to assess the statistical significance of the difference between two study group means. Statistical significance was defined as $P$ values $<0.05$ and highly significant as $P<0.001$.

Ethical considerations: An informed written consent was taken from all patients after explaining the purpose of the study. All pro- cedures were conducted according to the ethical standard approved by the Institutional Human Ethics Committee, Faculty of Medicine, Suez Canal University, Egypt.

\section{Results}

Molecular subtyping of the three Blastocystis isolates revealed that 2 isolates (isolate I and III) belong to subtype (ST) 3 and one isolate (isolate II) belong to ST1 (Fig. 1). In vitro effect of propolis extract and PVS on the mean counts of Blastocystis parasite after 24, 48 and $72 \mathrm{hr}$ were given (Tab. 1). Ethanol-treated cultures didn't show significant difference on the mean counts of the parasite compared to NTC at the same time of incubation. All isolates were susceptible to MTZ, with two concentrations (50 \& $100 \mu \mathrm{g} / \mathrm{ml}$ ) showed no growth after $24 \mathrm{hr}$, while the concentration of $10 \mu \mathrm{g} / \mathrm{ml}$ showed highly significant reduction in the parasite counts in all incubation periods $(24,48,72$ hr) with a cytocidal effect after $72 \mathrm{hr}$. Propolis extract inhibited the growth of Blastocystis parasites of the three isolates and the level of inhibition varied according to the extract concentration and incubation times. The highest reduction of parasite growth was observed in cultures exposed to 500 \& $1000 \mu \mathrm{g} / \mathrm{ml}$ of propolis, in all incubation periods $(24,48,72 \mathrm{hr})$ with the later concentration producing comparable results to MTZ $(10 \mu \mathrm{g} / \mathrm{ml})$ with a cytocidal effect after 72 hr. As regards to PVS, it showed a significant cytostatic effect on both isolate I \& III which also varied according to the concentration and incubation times with the highest concentration $(300 \mu \mathrm{g} / \mathrm{ml})$ showing the highest reduction of parasite counts. However, isolate II didn't show significant reduction of the parasite counts at all the used concentrations of PVS $(100,200,300 \mu \mathrm{g} / \mathrm{ml})$ and through all the incubation periods $(24,48,72 \mathrm{hr})$.

Propolis exerted a notable effect on Blastocystis morphology which was detected at higher concentrations $(500 \& 1000 \mu \mathrm{g} / \mathrm{ml})$, where the size rang of the vacuolar and granular forms was significantly smaller than that of the NTC $(P<0.001)$ and cultures 
challenged with other concentrations of propolis or PVS (Figs. 2 \& 3). The cultures treated with MTZ $(10 \mu \mathrm{g} / \mathrm{ml})$ also showed reduced size range. All concentrations of propolis extract, as well as PVS (200 \& $300 \mu \mathrm{g} / \mathrm{ml})$, showed increased percentages of

Table 1 Mean counts $\left(\times 10^{4}\right)$ and percentage of growth inhibition of Blastocystis parasites in culture challenged with graded concentrations of propolis extract and PVS.

\begin{tabular}{|c|c|c|c|c|c|c|}
\hline \multirow{3}{*}{$\begin{array}{l}\text { Treated / Non treat- } \\
\text { ed cultures (tested } \\
\text { concentration) }\end{array}$} & \multicolumn{6}{|c|}{ Time of incubation } \\
\hline & \multicolumn{2}{|c|}{$24 \mathrm{hr}$. } & \multicolumn{2}{|c|}{$48 \mathrm{hr}$. } & \multicolumn{2}{|c|}{$72 \mathrm{hr}$. } \\
\hline & Mean \pm SD & $\begin{array}{l}\% \text { Growth } \\
\text { inhibition }\end{array}$ & Mean \pm SD & $\begin{array}{l}\% \text { Growth } \\
\text { inhibition }\end{array}$ & Mean \pm SD & $\begin{array}{l}\% \text { Growth } \\
\text { inhibition }\end{array}$ \\
\hline \multicolumn{7}{|l|}{ Isolate I } \\
\hline NTC & $35 \pm 10.8$ & 00.0 & $117.6 \pm 8.7$ & 00.0 & $197.3 \pm 8.3$ & 00.0 \\
\hline ETC & $34.6 \pm 5$ & 1.1 & $107.3 \pm 12.8$ & 8.7 & $188.6 \pm 16.6$ & 4.7 \\
\hline $\operatorname{MTZ}(10 \mu \mathrm{g} / \mathrm{ml})^{* *}$ & $6.6 \pm 1.1$ & 81.1 & $1.3 \pm 0.5$ & 98.8 & 0 & 100 \\
\hline PE $\quad(125 \mu \mathrm{g} / \mathrm{ml})$ & $34.3 \pm 7.3$ & 2 & $117.3 \pm 3$ & 0.8 & $55 \pm 6.2 *$ & 72.1 \\
\hline $\mathrm{PE} \quad(250 \mu \mathrm{g} / \mathrm{ml})$ & $22.6 \pm 7.7$ & 35.4 & $50 \pm 8^{*}$ & 57.4 & $33.3 \pm 4.1^{*}$ & 83.1 \\
\hline PE $\quad(500 \mu \mathrm{g} / \mathrm{ml})^{* *}$ & $7.6 \pm 1.5$ & 78.2 & $10.6 \pm 2.3$ & 90.9 & $2.3 \pm 1.1$ & 98.8 \\
\hline PE $(1000 \mu \mathrm{g} / \mathrm{ml})^{* *}$ & $4.6 \pm 1.5$ & 86.8 & $4.3 \pm 1.1$ & 96.3 & 0 & 100 \\
\hline PVS $(100 \mu \mathrm{g} / \mathrm{ml})$ & $15.3 \pm 1.1^{*}$ & 56.2 & $70.3 \pm 16.5^{*}$ & 40.2 & $182.6 \pm 2.3$ & 7.4 \\
\hline PVS $(200 \mu \mathrm{g} / \mathrm{ml})$ & $7.3 \pm 0.5^{* *}$ & 79.1 & $36.3 \pm 4 *$ & 69.1 & $66.6 \pm 13.2 *$ & 66.2 \\
\hline PVS $(300 \mu \mathrm{g} / \mathrm{ml})^{* *}$ & $6.3 \pm 0.5$ & 82 & $9.3 \pm 2.3$ & 92 & $2.3 \pm 3.2$ & 98.8 \\
\hline \multicolumn{7}{|l|}{ Isolate II } \\
\hline NTC & $57.3 \pm 9$ & 00.0 & $119.3 \pm 6$ & 00.0 & $207.3 \pm 1.1$ & 00.0 \\
\hline ETC & $48.6 \pm 6.3$ & 15.1 & $108.6 \pm 7.5$ & 8.9 & $194 \pm 8.7$ & 6.4 \\
\hline $\operatorname{MTZ}(10 \mu \mathrm{g} / \mathrm{ml})^{* *}$ & $5.0 \pm 1$ & 91.2 & $3.3 \pm 1.1$ & 97.2 & 0 & 100 \\
\hline $\mathrm{PE} \quad(125 \mu \mathrm{g} / \mathrm{ml})$ & $48.3 \pm 4.9$ & 15.7 & $104.6 \pm 7.0$ & 12.3 & $113.3 \pm 15.2 *$ & 45.3 \\
\hline PE $\quad(250 \mu \mathrm{g} / \mathrm{ml})^{* *}$ & $17.6 \pm 0.5$ & 69.2 & $33.6 \pm 3.2$ & 71.8 & $23.3 \pm 1.1$ & 88.7 \\
\hline PE $\quad(500 \mu \mathrm{g} / \mathrm{ml})^{* *}$ & $14.3 \pm 1.1$ & 75.0 & $2.0 \pm 0.0$ & 98.3 & $2.0 \pm 0$ & 99 \\
\hline PE $(1000 \mu \mathrm{g} / \mathrm{ml}) * *$ & $7.3 \pm 1.5$ & 87.2 & $1.6 \pm 0.5$ & 98.6 & 0 & 100 \\
\hline PVS $(100 \mu \mathrm{g} / \mathrm{ml})$ & $53 \pm 2.6$ & 7.5 & $109.3 \pm 8.3$ & 8.3 & $196 \pm 14.4$ & 5.4 \\
\hline PVS $(200 \mu \mathrm{g} / \mathrm{ml})$ & $49.3 \pm 1.1$ & 13.9 & $114.6 \pm 11$ & 3.9 & $194.6 \pm 9.4$ & 6.12 \\
\hline PVS $(300 \mu \mathrm{g} / \mathrm{ml})$ & $46.6 \pm 1.1$ & 18.6 & $101.3 \pm 2.3$ & 15 & $189.3 \pm 14$ & 8.6 \\
\hline \multicolumn{7}{|l|}{ Isolate III } \\
\hline NTC & $45 \pm 3.6$ & 00.0 & $159.3 \pm 7.5$ & 00.0 & $227.3 \pm 16.1$ & 00.0 \\
\hline ETC & $36 \pm 4$ & 20.0 & $133.3 \pm 7.5$ & 16.3 & $218.6 \pm 1.1$ & 3.7 \\
\hline MTZ $(10 \mu \mathrm{g} / \mathrm{ml})^{* *}$ & $5.6 \pm 0.5$ & 87.5 & $2.3 \pm 1.1$ & 98.5 & 0 & 100 \\
\hline $\mathrm{PE} \quad(125 \mu \mathrm{g} / \mathrm{ml})$ & $44.6 \pm 7.5$ & 0.8 & $143.6 \pm 2$ & 9.8 & $72.3 \pm 3.7^{* *}$ & 68.1 \\
\hline $\mathrm{PE} \quad(250 \mu \mathrm{g} / \mathrm{ml})$ & $24 \pm 8$ & 46.6 & $110.3 \pm 3.7^{*}$ & 30.7 & $42.3 \pm 7.5^{* *}$ & 81.3 \\
\hline $\mathrm{PE} \quad(500 \mu \mathrm{g} / \mathrm{ml})^{* *}$ & $9.3 \pm 0.5$ & 79.3 & $4.3 \pm 0.5$ & 79.3 & $2.0 \pm 0$ & 99.1 \\
\hline PE $(1000 \mu \mathrm{g} / \mathrm{ml})^{* *}$ & $4.6 \pm 2.3$ & 89.7 & $1.6 \pm 0.5$ & 98.9 & 0 & 100 \\
\hline PVS $(100 \mu \mathrm{g} / \mathrm{ml})$ & $23.6 \pm 1.5^{*}$ & 47.5 & $123.3 \pm 5$ & 22.5 & $152 \pm 14.7^{*}$ & 33.0 \\
\hline PVS $(200 \mu \mathrm{g} / \mathrm{ml})^{*}$ & $23.6 \pm 1.5$ & 47.5 & $99.3 \pm 16.2$ & 37.6 & $116.3 \pm 10.5$ & 48.8 \\
\hline PVS $(300 \mu \mathrm{g} / \mathrm{ml})$ & $17.6 \pm 2.5^{*}$ & 60.8 & $43.6 \pm 3.5 * *$ & 72.6 & $72.6 \pm 9 * *$ & 68 \\
\hline
\end{tabular}

$* P<0.05=$ significant difference in comparison to NTC at same time of incubation, ${ }^{* *} P<0.001=$ highly signifi-

cant difference in comparison to NTC at the same time of incubation, PE, propolis extract granular forms counted at $48 \mathrm{hr}$. compared to NTC which showed shriveled appearance and was especially abundant at concentration of $1000 \mu \mathrm{g} / \mathrm{ml}(52 \%)$ replacing the typical vacuolar forms (Figs. $2 \& 4$ ). 


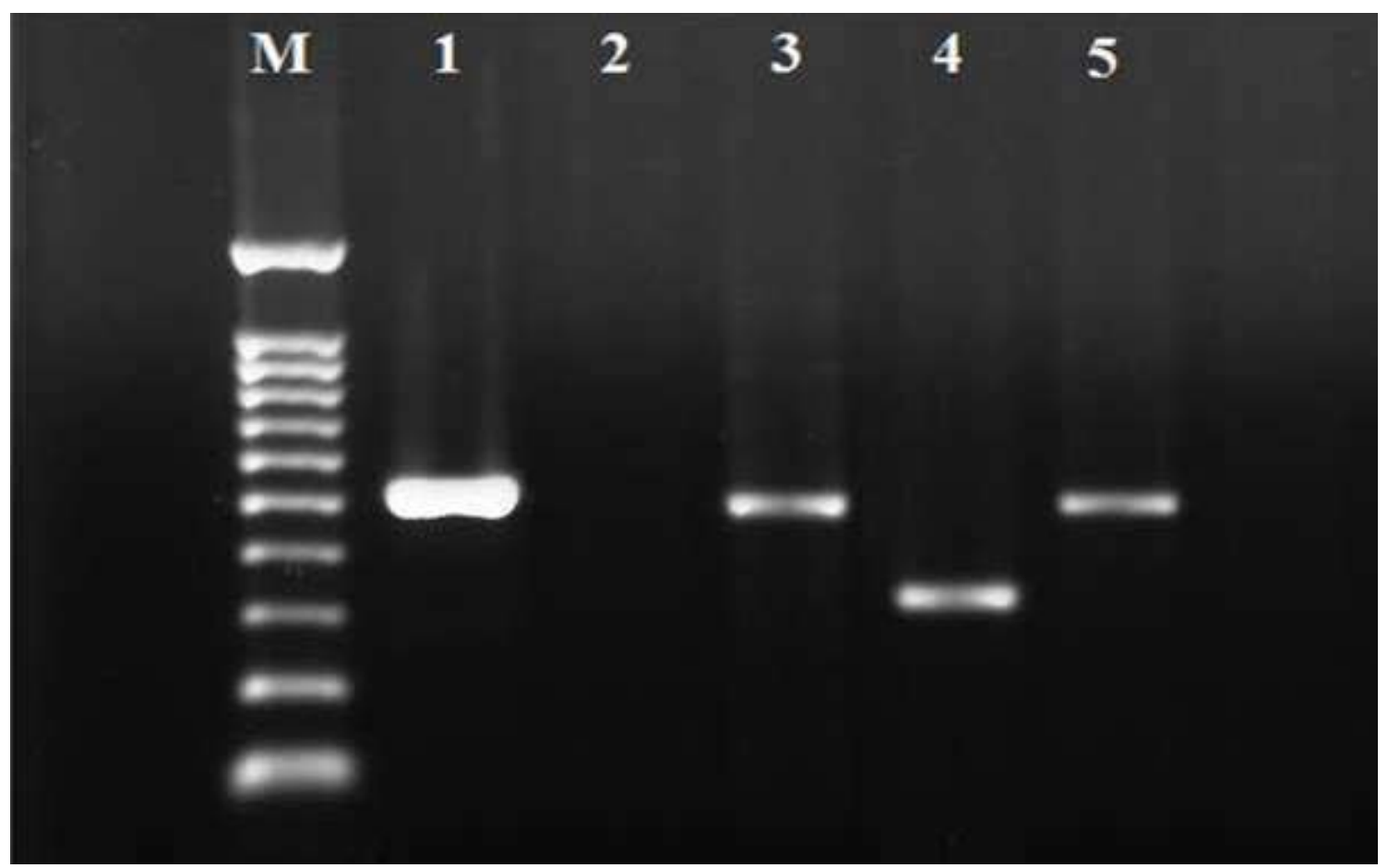

Fig. 1: PCR products of Blastocystis spp. on $1.5 \%$ agarose gel stained with ethidium bromide showing; M, molecular weight marker (100 bp), lane 1 a positive control for ST3 at $526 \mathrm{bp}$, lane 2 negative control, lanes 3 and 5 represent isolates I and III (ST3) and lane 4 represents isolate II (ST1 at $351 \mathrm{bp})$.

\section{Discussion}

Blastocystis spp. is considered as one of the commonest enteric protozoan parasites infecting humans worldwide. Despite its controversial clinical significance, accumulating reports suggest its pathogenic potential (Tan, 2008b). There is a consensus that therapy should be limited to persistently symptomatic patients after screening for alternative etiologies (Stensvold et al, 2010; Dinleyici et al, 2011). Several antiprotozoal drugs have been used to treat blastocystosis, but with variable rates of efficacy (Mirza et al, 2011; Robert et al, 2015). Among which MTZ stands as the first-line treatment, however development of drug resistance and its unpleasant adverse effects complicates its use suggesting that current treatment guidelines should be revised (Stensvold et al, 2010; Robert et al, 2015). Thus, there is a need to search for new treatment alternatives to target Blastocystis. In the present study, we have evaluated the in vitro antiprotozoal activity of ethanolic extract of Egyptian propolis and a cysteine protease inhibitor, PVS against Blastocystis spp. which, to the present best knowledge, was not assessed before by any reports.

The present isolates showed infection with ST1 \& ST3. These subtypes were reported as the mostly detected subtypes worldwide and also in Egypt, with ST3 being the most prevalent (Souppart et al, 2009 and 2010; Abaza et al, 2014). Various reports have proven that the viable cell count method, applied in this study, was a reliable method to determine the activity of plant extracts against Blastocystis spp. (Yakoob et al, 2011; El-Deeb et al, 2012; Girish et al, 2015). In the present study, no MTZ resistant strains were detected. Similarly, Yakoob et al. (2011) reported sensitivity of all Blastocystis isolates from healthy controls to MTZ at concentrations of 0.01 and $0.1 \mathrm{mg} / \mathrm{ml}$, these isolates were mostly ST3 and coinfection of ST3 and ST1, however in 
the same study isolate from IBS patients showed variable efficacy to MTZ and were mostly of ST1. Another recent study demonstrated high growth inhibition of MTZ (0.1 and $1 \mathrm{mg} / \mathrm{ml}$ ) against ST1, ST3 and ST5 (Girish et al, 2015). Moreover, several clinical studies reported effective parasite clearance with MTZ (Nigro et al, 2003; Aguilar and Lucía, 2010). This controversy about MTZ efficacy may be attributed to intrasubtype differences in mechanisms of susceptibility to the drug, possibly due to presence of different alleles of each subtype (Roberts et al, 2015).

The use of ethanol (70\%) as a solvent for propolis extract had no significant effect on the growth of Blastocystis parasites in all isolates throughout the experiment. Similarly, the use of $95 \%$ ethanol demonstrated no activity on Blastocystis spp. as reported by Vital and Rivera (2009). In the present study, high concentration of propolis extract $(1000 \mu \mathrm{g} / \mathrm{ml})$ exhibited potent inhibitory effect on the in vitro growth of Blastocystis spp. regardless of ST difference with complete eradication of the parasite after $72 \mathrm{~h}$ which were comparable to results obtained by the reference drug (MTZ) at $10 \mu \mathrm{g} / \mathrm{ml}$ concentration. Reports highlighted the activity of propolis extract against intracellular and extracellular protozoan parasites; Fidalgo et al. (2011) evaluated the effect of eight Cuban propolis samples from different geographical locations where all samples showed inhibitory effect on L. amazonenzis while only five samples decreased the viability of $T$. vaginalis trophozoites. Also, Monzote et al. (2012) demonstrated major antiprotozoan activity against $T$. brucei, $T$. cruzi, P. falciparum and $L$. infantum using 20 different samples of red, brown and yellow Cuban propolis (YCP). They suggested that several bioactive compounds, with significant association with the YCP, could be responsible for the antimicrobial activities. Another study specified acetyl triterpenes as possible responsible constituents for this antimicrobial activity in YCP (Marquéz et al,
2010). The chemical composition of a raw Egyptian propolis sample from Dakahlia Governorate was investigated by Hegazi et al. (2004), where 65 compounds were recognized among which some new triterpenoids including lupeol and alpha-amyrin and two new caffeate esters were identified. Moreover, the Egyptian propolis showed highly significant antigiardial activity over the MTZ after 6 days of experimental mice infection (Abdel-Fattah and Nada, 2007). Propolis extract at high concentrations (8-16 $\mathrm{mg} / \mathrm{ml}$ ) also demonstrated potent amoebicidal effect on both trophozoites and cysts of Acanthamoeba castellanii (Topalkara et al, 2007).

In the present study, the effect of PVS was evident on ST3 isolates with significant reduction of cell counts especially with the highest concentration $(300 \mu \mathrm{g} / \mathrm{ml})$, while it showed minimal effect on ST1 isolate. Blastocystis cysteine proteases were reported to degrade human secretory immunoglobulin A and induced up-regulation of interleukin 8, resulting in tissue damage and GIT disturbances, suggesting that proteases are potential virulence factors and contribute to parasite survival in vivo (Puthia et al, 2008). Recently, PVS was shown to inhibit the growth of C. parvum in mammalian cell line where high percentage of mice survived the infection compared to infected controls, moreover, it exhibited no toxicity in vitro or in vivo (Ndao et al, 2013).

On the other hand, two cysteine protease inhibitors (iodoacetamide \& E-64) were investigated as potential chemotherapeutic agents against Blastocystis spp. and proved high susceptibility against all studied Blastocystis isolates (ST-1, 3, 4 \& 7) in vitro (Mirza et al, 2011; Al-Mohammed et al, 2013). The variable effect of the PVS noted in this study could be attributed to subtypedependent variability in susceptibility of Blastocystis spp. to PVS. This was previously suggested by Mirza et al. (2011), they examined four Blastocystis isolates with the ST4 and ST7 infection, and demonstrated 
that the subtype-dependent variation in the susceptibility to the six different antiprotozoal drugs including MTZ. Indeed, large number of samples of the individual subtype infection was required to clearly demonstrate such variation.

In the present study, light microscopic observations of the morphology of treated Blastocystis parasites revealed significant reduction in the size range of vacuolar and granular forms exposed to high doses of propolis extract $(500$ and $1000 \mu \mathrm{g} / \mathrm{ml})$, moreover size reduction was also noted with cultures treated with MTZ $(10 \mu \mathrm{g} / \mathrm{ml})$. When keeping with the present findings, G. lambia trophozoites exposed to propolis extract exhibited changes of the pear-shaped appearance of cells with reduction of flagellar beating frequency (Freitas et al, 2006).

Furthermore, the MTZ treated Blastocystis cells have shown cell shrinkage with compaction of organelles in the cytoplasm using light microscopy. Such features were considered the important morphological evidence of apoptosis (Nasirudeen et al, 2004), which could be attributed to the loss of cytoplasmic fluids and denaturation of proteins in the apoptotic cells (Huppertz et al, 1999). The morphological changes observed here suggested that the propolis extract could have similar effects on Blastocystis spp. to that obtained by MTZ which has been suggested to activate the apoptotic machinery (Nasirudeen et al, 2004). Another light microscopic observation in this study was the abundance of granular forms with shriveled appearance at $48 \mathrm{~h}$ incubation especially in cultures treated with high doses of propolis extract and PVS. Similar finding was observed on in vitro treatment of Blastocystis spp. ST3 with Ferula asafoetida (oleo-gumresin) using both powder and oil forms with high concentrations $(20$ and $50 \mathrm{mg} / \mathrm{ml}$, respectively), where the viable vacuolar forms were replaced by granular forms which lost viability overtime and eventually disintegrated (El-Deeb et al, 2012).

The previous study has proposed that the granular forms may represent the sequential stages of the cell degeneration (Vdovenko, 2000) which could explain the present study outcome data.

\section{Conclusion}

Both the propolis extract and PVS showed potent inhibitory effect on Blastocystis spp. However, unlike PVS, propolis extract has shown complete eradication of the parasite and uniform effect across the studied subtypes and this was comparable to MTZ (reference drug). Further studies are needed to evaluate the effect of propolis on larger number of isolates and on other subtypes especially showing MTZ resistance and to evaluate its effect in vivo.

In addition, there is a need to study propolis from different geographical locations in Egypt with identification of its bioactive principles to achieve standardization before being introduced to clinical practice. Ongoing studies using other subtypes \& MTZ resistant isolates with further evaluation of its effect in vivo will be published in due time.

\section{References}

Abaza, SM, El-Moamly, AA, Ismail, OA, Alabbassy, MM, 2013: Cysteine proteases inhibitors (phenyl vinyl sulfone and valproic acid) in treatment of schistosomiasis mansoni-infected mice: An experimental study to evaluate their role in comparison to praziquantel. P.U.J. 6, 1:99-108.

Abaza, SM, Rayan, HZ, Soliman, RH, Ne-mr, NA, Mokhtar, AB, 2014: Subtype analysis of Blastocystis spp. isolates from symptomatic and asymptomatic patients in Suez Canal University Hospitals, Ismailia, Egypt. P.U.J. 7, 1:56-67.

Abdel-Fattah, N, Nada, O, 2007: The effect of propolis versus metronidazole and their combined use in treatment of acute experimental giardiasis. J. Egypt. Soc. Parasitol. 37, 2:S691710.

Aguilar, C, Lucía, JF, 2010: An overview of Blastocystis hominis infection and published experience in hemophilic population. J Coagul. Disord. 2:1-4.

Ahmed, MAF, Ismail, KA, Ahmed, SAEG, Ibrahim, AN, Gohar, YM. 2015: In Vitro activity of curcumin and silver nanoparticles against Blastocystis hominis. Infect. Dis. Clin. Pract. 
23, 3:135-40.

Alfellani, MA, Taner-Mulla, D, Jacob, AS Imeede, CA, Yoshikawa, H, et al, 2013: The genetic diversity of the Blastocystis spp. in the livestock and zoo animals. Protist. 164:497-509.

Al-Mohammed, HI, Hussein, EM Aboulmagd E, 2013: Effect of green tea extract and cysteine proteases inhibitor (E-64) on symptomatic genotypes of Blastocystis hominis in vitro and in infected animal model. Int. J. Curr. Microbiol. App. Sci. 2, 12:228-39.

Arisue, N, Hashimoto, T, Yoshikawa, H, Nakamura, Y, Nakamura, et al, 2002: Phylogenetic position of Blastocystis hominis and of Stramenopiles inferred from multiple molecular sequence data. J. Eukaryot. Microbiol. 49:42-53.

Atkinson, HJ, Babbitt, PC, Sajid, M, 2009: The global cysteine peptidase landscape in parasites. Trends Parasitol. 25, 12:573-81.

Bankova, V, 2005: Chemical diversity of propolis and the problem of standardization. J. Ethnopharmacol. 100, 1:114-7.

Bankova, V, De Castro, S, Marcucci, M, 2000: Propolis: Recent advances in chemistry and plant origin. Apidologie 31, 1:3-15.

Bueno-Silva, B, Alencar, SM, Koo, H, Ikegaki, M, Silva, GV, et al, 2013: Antiinflammatory and antimicrobial evaluation of neovestitol and vestitol isolated from Brazilian red propolis. J. Agric. food Chem., 61, 19: 454650.

Calzada, F, Yepez-Mulia, L, Tapia-Contreras, A, 2007: Effect of Mexican medicinal plant used to treat trichomoniasis on Tricho-monas vaginalis trophozoites. J. Ethnopharmacol. 113:248-51.

Cheesbrough, M, 2006: District Laboratory Practice in Tropical Countries: Cambridge university press, United Kingdom.

Dinleyici, EC, Eren, M, Dogan, N, Reyhanioglu, S, Yargic, ZA, et al, 2011: Clinical efficacy of Saccharomyces boulardii or metronidazole in symptomatic children with Blastocystis hominis infection. Parasitol. Res. 108, 3:541-5.

Dogruman-Al, F, Simsek, Z, Boorom, K, Ekici, E, Sahin, M, et al, 2010: Comparison of methods for detection of Blastocystis infection in routinely submitted stool samples, and also in IBS/IBD Patients in Ankara, Turkey. PLoS One 5, 11:e15484.Dunn, L, Tan, K, Vanelle, P, Juspin, T, Crozet, M, et al, 2012: Development of metronidazole-resistant lines of Blastocystis $s p$. Parasitol Res. 111, 1:441-50.

El Safadi, D, Gaayeb, L, Meloni, D, Cian, A, Poirier, P, et al, 2014: Children of Senegal River Basin show the highest prevalence of Blastocystis $s p$. ever observed worldwide. BMC Infect. Dis. 14, 1:1-9.

El-Deeb, HK, Al-Khadrawy, FM, El-Hameid, AKA, 2012: Inhibitory effect of Ferula asafoetida L. (Umbelliferae) on Blastocystis spp. subtype 3 growth in vitro. Parasitol. Res. 111, 3:1213-21.

Engel, JC, Doyle, PS, Hsieh, I, McKerrow, JH, 1998: Cysteine protease inhibitors cure an experimental Trypanosoma cruzi infection. J. Exp. Med. 188, 4:725-34.

Fidalgo, ML, Ramos, SI, Parra, GM, CuestaRubio, O, Hernández, MI, et al, 2011: Activity of Cuban propolis extracts on Leishmania amazonensis and Trichomonas vaginalis. Nat. Prod. Commun. 6, 7:973-6.

Freitas, S, Shinohara, L, Sforcin, J, Guimarães, S, 2006: In vitro effects of propolis on Giardia duodenalis trophozoites. Phytomedicine 13, 3:170-5.

Garcia, LS, 2007: Diagnostic Medical Parasitology, $5^{\text {th }}$ ed. ASM Press, Washington, D.C.

Girish, S, Kumar, S, Aminudin, N, 2015: Tongkat Ali (Eurycoma longifolia): A possible therapeutic candidate against Blastocystis $s p$. Parasite.Vector 8:332-8.

Grabensteiner, E, Liebhart, D, Arshad, N, Hess, M, 2008: Antiprotozoal activities determined in vitro and in vivo of certain plant extracts against Histomonas meleagridis, Tetratrichomonas gallinarum and Blastocystis sp. Parasitol. Res. 103, 6:1257-64.

Greenaway, W, Scasbroock, T, Whatley, F R, 1990: The composition and plant origins of propolis: a report of work at Oxford. Bee World 71, 3:107-18.

Gupta, R, Parsi, K, 2006: Chronic urticaria due to Blastocystis hominis. Australas. J. Dermatol. 47:117-9.

Hameed, DMA, Hassanin, OM, Zuel-Fak-kar, NM, 2011: Association of Blastocystis hominis genetic subtypes with urticaria. Parasitol. Res. 108:553-60.

Hegazi, AG, Abd El Hady, FK, El Menway, FA, Al Mehdar, H, 2004: Egyptian propolis: 5 influence of propolis administration on some chicken biochemical parameters. J. Appl. Vet. 
Sci. Tech. 1:43-58.

Hegazi, AG, El Hady, FKA, Shalaby, HA, 2007: An in vitro effect of propolis on adult worms of Fasciola gigantic. Vet. Parasitol. 144, 3:279-86.

Huang, S, Zhang, CP, Wang, K, Li, GQ, Hu, FL, 2014: Recent advances in the chemical composition of propolis. Molecules 19, 12: 19610-32.

Huppertz, B, Frank, HG, Kaufmann, P, 1999: The apoptosis cascade, morphological and immunohistochemical methods for its visualization. Anat. Embryol. 200:1-18.

Ito, J, Chang, FR, Wang, HK, Park, YK, Ikegaki, M, et al, 2001: Anti-AIDS agents. 48. 1 Anti-HIV activity of moronic acid derivatives and the new melliferone-related triterpe-noid isolated from Brazilian propolis. J. Nat. Prod. 64, 10:1278-81.

Jones, MS, Whipps, CM, Ganac, RD, Hudson, NR, Boroom, K, 2009: Association of Blastocystis subtype 3 and 1 with patients from an Oregon community presenting with chronic gastrointestinal illness. Parasitol. Res. 104:3415.

Larson, ET, Parussini, F, Huynh, MH, Giebel, JD, Kelley, AM, et al, 2009: Toxoplasma gondii cathepsin L is the primary target of the invasion-inhibitory compound morpholi-nurealeucyl-homophenyl-vinyl sul-fone phenyl. J. Biol. Chem. 284, 39:26839-50.

Leelayoova, S Taamasri, P, Rangsin, R, Naaglor, T, Thathaisong, $\mathrm{U}$, et al, 2002: In vitro cultivation: A sensitive method for detecting Blastocystis hominis. Ann. Trop. Med. Parasitol. 96:803-7.

Marquéz, I, Cuesta-Rubio, O, Campo, M, Rosado, A, Montes de Oca, R, et al, 2010: Studies on the constituents of yellow Cuban propolis: GC-MS determination of triterpenoids and flavonoids. J. Agric. Food Chem. 58:4725-30.

Miorin, P, Levy Junior, N, Custodio, A, Bretz, W, Marcucci, M, 2003: Antibacterial activity of honey and propolis from Apis mellifera and Tetragonisca angustula against Staphylococcus aureus. J. Appl. Microbiol. 95, 5:913-20.

Mirza, H, Teo, JD, Upcroft, J, Tan, KS, 2011: A rapid, high-throughput viability assay for Blastocystis spp. reveals metronidazole resistance and extensive subtype-dependent variations in drug susceptibilities. Antimicrob. Agents Chemother. 55, 2:637-48.
Monzote, L, Cuesta-Rubio, O, Fernandez, M, Márquez Hernandez, I, Fraga, et al, 2012: In vitro antimicrobial assessment of Cuban propolis extracts. Mem. Inst. Oswaldo Cruz 107, 8:97884.

Nasirudeen, AMA, Hian, YE, Singh, M, Tan, KSW, 2004: Metronidazole induces the programmed cell death in the protozoan parasite Blastocystis hominis. Microbiology 150:33-43.

Nassir, E, Awad, J, Abel, AB, Khoury, J, Shay, M, et al, 2004: Blastocystis hominis as a cause of hypoalbuminemia and anasarca. Eur. J. Clin. Microbiol. Infect. Dis. 23:399-402.

Ndao, M, Nath-Chowdhury, M, Sajid, M, Marcus, V, Mashiyama, ST, et al, 2013: A cysteine protease inhibitor rescues mice from a lethal Cryptosporidium parvum infection. Antimicrob. Agents Chemother. 57, 12:6063-73.

Nigro, L, Larocca, L, Massarelli, L, Patamia, I, Minniti, S, et al, 2003: A placebo-controlled treatment trial of Blastocystis hominis infection with metronidazole. J. Travel. Med. 10:128-30.

Pandey, KC, Singh, N, Arastu-Kapur, S, Bogyo, M, Rosenthal, PJ, 2006: Falstatin, a cysteine protease inhibitor of Plasmodium falciparum, facilitates erythrocyte invasion. PLoS Pathol. 2, 11:e117.

Popolo, A, Piccinelli, LA, Morello, S, CuestaRubio, O, Sorrentino, R, et al, 2009: Antiproliferative activity of brown Cuban propolis extract on human breast cancer cells. Nat. Prod. Commun. 4, 12:1711-6.

Puthia, MK, Lu, J, Tan, KS, 2008: Blastocystis ratti contains cysteine proteases that mediate interleukin-8 response from human intestinal epithelial cells in an NF-kappaB-dependent manner. Eukaryot. Cell 7:435-43.

Rayan, HZ, Ismail, OA, El-Gayar, EK, 2007: Prevalence and clinical significance of Dientamoeba fragilis infections in patients suspected to have intestinal parasitic infection. J. Egypt Soc. Parasitol. 37, 2:599-608.

Roberts, T, Bush, S, Ellis, J, Harkness, J, Stark, D, 2015: In Vitro Antimicrobial susceptibility patterns of Blastocystis. Antimicrob. Agents Chemother., 59(8): 4417-4423.

Sajid, M, McKerrow, JH, 2002: Cysteine proteases of parasitic organisms. Mol. Bio-chem. Parasitol., 120(1): 1-21.

Sawangjaroen, N, Sawangjaroen, K, 2005: The effects of extracts from anti-diarrheic Thai medicinal plants on the in vitro growth of the 
intestinal protozoa parasite: Blastocystis hominis. J. Ethnopharmacol. 98, 2:67-72.

Sforcin, J, Orsi, R, Bankova, V, 2005: Effect of propolis, some isolated compounds and its source plant on antibody production. J. Ethnopharmacol. 98, 3:301-305.

Shah, M, Tan, CB, Rajan, D, Ahmed, S, Subramani, K, et al, 2012: Blastocystis hominis and Endolimax nana co-infection resulting in chronic diarrhea in an immunocompetent male. Case Rep. Gastroenterol. 6, 2:358-64.

Souppart, L, Sanciu, G, Cian, A, Wawrzyniak, I, Delbac, F, et al, 2009: Molecular epidemiology of human Blastocystis isolates in France. Parasitol. Res., 105, 2:3-17.

Souppart, L, Moussa, H, Cian, A, Sanciu, G, Poirier, P et al, 2010: Subtype analysis of Blastocystis isolates from symptomatic patients in Egypt. Parasitol. Res. 106:505-11.

Stensvold, CR 2013: Blastocystis: Genetic diversity and molecular methods for diagnosis and epidemiology. Trop Parasitol., 3(1): 26-34.

Stensvold, CR, Lewis, HC, Hammerum, A M, Porsbo, LJ, Nielsen, SS, et al, 2009: Blastocystis: unravelling potential risk factors and clinical significance of a common but neglected parasite. Epidemiol. Infect. 137, 11:1655-63.

Stensvold, CR, Smith, HV, Nagel, R, Olsen, KE, Traub, RJ, 2010: Eradication of Blastocystis carriage with antimicrobials: reality or delusion? J. Clin. Gastroenterol. 44, 2: 85-90.

Tan, KS, 2008a: Blastocystis spp. In: Emerging Protozoan Pathogens. $1^{\text {st }}$ Ed. Khan, N.A., Taylor and Francis, Oxford; The United Kingdom.

Tan, KS, 2008b: New insights on classification, identification, and clinical relevance of Blastocystis spp. Clin. Microbiol. Rev. 21:639-65.

Tan, TC, Suresh, KG, Smith, HV, 2008: Phenotypic and genotypic characterization of Blastocystis hominis isolates implicates subtype 3 as a subtype with pathogenic potential. Parasitol. Res. 104:85-93.

Topalkara, A, Vural, A, Polat, Z, Toker, M I, Arici, MK et al, 2007: In vitro amoebicidal activity of propolis on Acanthamoeba castellanii. J. Ocul. Pharmacol. Ther. 23, 1:40-5.
Ustün, S, Turgay, N, 2005: Blastocystis hominis and bowel diseases. Turkiye Parazitol. Derg. 30, 1:72-6.

Vdovenko, AA, 2000: Blastocystis hominis: origin and significance of vacuolar and granular forms. Parasitol. Res. 86, 4:8-10.

Vdovenko, AA, Williams, JE, 2000: Blastocystis hominis: neutral red supravital staining and its application to in vitro drug sensitivity testing. Parasitol. Res. 86, 7:573-581.

Vital, PG, Rivera, WL, 2009: Antimicrobial activity and cytotoxicity of Chromolaena odorata (L. f.): King and Robinson and Uncaria perrottetii (A. Rich) Merr. extracts. J. Med. Plants. Res. 3, 7:511-8.

Wang, K, Ping, S, Huang, S, Hu, L, Xuan, H, et al, 2013: Molecular mechanisms underlying the in vitro anti-inflammatory effects of a Ffavonoid-rich ethanol extract from Chinese propolis (poplar type). Evid. Based Complement. Alternat. Med. 127672.

Wong, KH, Ng, GC, Lin, RT, Yoshikawa, H,Taylor, MB, et al, 2008: Predominance of subtype 3 among Blastocystis isolates from a major hospital in Singapore. Parasitol. Res. 102:663-70.

Yakoob, J, Abbas, Z, Beg, MA, Naz, S, SafiaAwan, S, et al, 2011: In vitro sensitivity of Blastocystis hominis to garlic, ginger, white cumin, and black pepper used in diet. Parasitol. Res. 109, 2:379-85.

Yakoob, J, Jafri, W, Asim Beg, M, Abbas, Z, Naz, S, et al, 2010: Blastocystis hominis and Dientamoeba fragilis in patients fulfilling irritable bowel syndrome criteria. Parasitol. Res. 107:679-84.

Yoshikawa, H, Dogruman-AI, F, Turk, S, Kustimur, S, Balaban, N, et al, 2011: Evaluation of DNA extraction kits for molecular diagnosis of human Blastocystis subtypes from fecal samples. Parasitol. Res. 109, 4:1045-50.

Yoshikawa, H, Wu, Z, Kimata, M, Iseki, I, Ali, M, et al, 2004: PCR-based genotype classification among human Blastocystis hominis population isolated from different countries. Parasitol. Res. 92:22-9

\section{Explanations of figures}

Fig. 2: Blastocystis parasite showing (a) vacuolar forms with large size in NTC, compared to (b) vacuolar forms with small size (x400) in $48 \mathrm{hr}$ cultures treated with propolis extract $(1000 \mu \mathrm{g} / \mathrm{ml})$, bars $=10 \mu \mathrm{m}$ (c) abundance of granular forms (x1000) in $48 \mathrm{hr}$ cultures treated with propolis extract $(1000 \mu \mathrm{g} / \mathrm{ml})$, (d) viable cell (unstained) and unviable cell (stained with Trypan blue), $\mathrm{x} 400$.

Fig. 3: Size ranges of Blastocystis parasites in treated cultures in comparison to non-treated control at $48 \mathrm{hr}$ Fig. 4: Percentage of granular forms in treated cultures in comparison to non-treated control at $48 \mathrm{hr}$, 

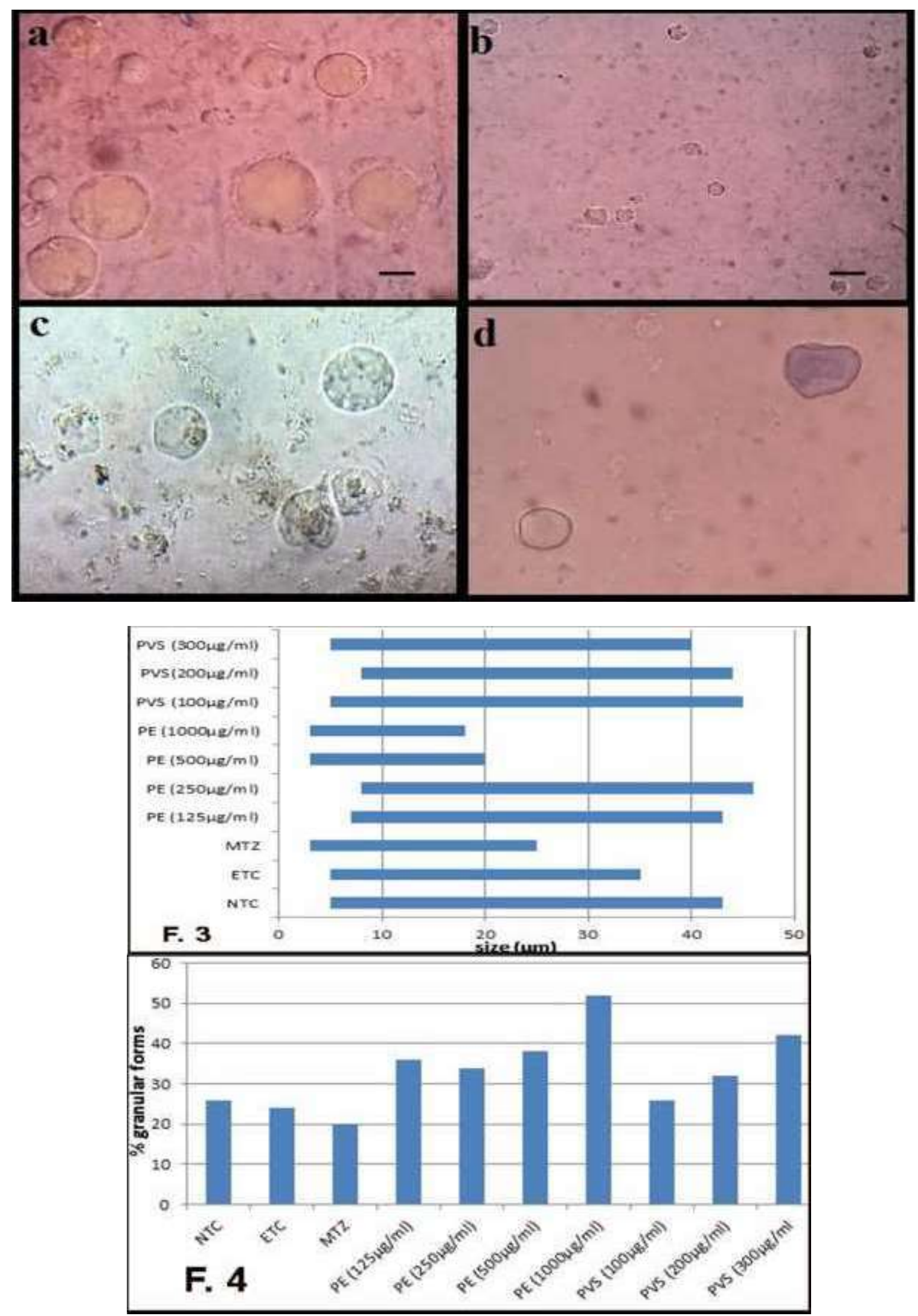